\title{
Arbor
}

\section{El infante Don Gabriel y el Impresor Ibarra en la obra cumbre del Salustio}

\author{
Juan B. Olaechea Labayen
}

Arbor CLVI, 616 (Abril 1997) 99-130 pp.

En la obra conocida como el "Salustio de Ibarra", considerada por especialistas domésticos y foráneos como la mejor impresa en España, convergen circunstancias relevantes debidas a la participación intelectual del infante don Gabriel de Borbón y la eficiencia técnica de Joaquin Ibarra. El autor reivindica la autenticidad de los textos atribuidos al infante contra cierto excepticismo sembrado en razón de la elevada alcurnia de la atribución. Seguidamente, se realiza el análisis de las cualidades técnicas de la impresión, eminentes en una época de esplendor del arte impresorio, y en cuya confección colaboraron los más descollantes artistas del buril de aquel periodo considerado de triunfo de la estampa ilustrada.

La época más floreciente del arte tipográfico en España, coincidiendo con el esplendor del arte parejo del grabado, se desarrollo, sin duda alguna, durante el largo reinado de Carlos III (1759-1788). De las prensas y tórculos de aquellos años, regentados por eximios artífices, salió un largo cúmulo de obras maestras, descollantes a nivel internacional, que, en parte, deberán ser evocadas por su relación con el tema a lo largo de este trabajo, así como los artífices de las mismas. 
De entre dichas obras hay una que merece ser destacada de forma especial, a la que muchos consideran como la mejor obra impresa nunca en España, conocida por el «Salustio de Ibarra", que comprende el texto original y su versión española de dos libros del historiador romano Cayo Salustio Crispo, La Conjuración de Catilina y La Guerra de Yugurta, en cuya impresión del año 1772 en un amplio volumen en folio por Joaquín Ibarra, convergen una serie de circunstancias relevantes, entre las que cabe anticipar la implicación de la Casa Real con la participación eminente del infante don Gabriel Antonio de Borbón, cuya destacada labor en este asunto no ha obtenido todavía el reconocimiento que en justicia le corresponde. Pero antes de entrar en los pormenores históricos de esta publicación y en el análisis artístico de la misma, no estará de más evocar algunos juicios emitidos sobre dicha obra que justifiquen interesar la atención del lector.

\section{Testimonios Laudatorios del Salustio}

«El Salustio de Ibarra es, sin duda, el mejor libro impreso en España" (Nestor Luján). "Una de las obras cumbre de la imprenta española...que mayor fama ha dado a la imprenta española» (Carrete Parrondo). «Esta obra tiene fama de ser la más bien impresa en España...es más: puede que supere en belleza tipográfica a las mejores producciones de Didot, Bodoni, Renouard, Crapelet y demás maestros del arte de la imprenta" (Palau). "Calificado como el mejor impreso en España...superando en belleza a las mejores producciones de Bodoni y otros famosos maestros del Arte" (Ruiz Lasala). "Para algunos, la obra mejor impresa de Ibarra" (H. Escolar).

Frente al testimonio de los autores domésticos que sitúan esta obra a la cabeza de todas las que más alabanzas han obtenido en la historia del libro español, cabe presentar un florilegio espigado de autores extranjeros que suscita cierto orgullo patrio: «Joaquín Ibarra fue el impresor español que alcanzó mayor reputación no sólo en España, sino a lo largo de Europa. La magnífica edición del Salustio está considerada como su pieza maestra...Como toda gran obra 
impresa produce la sensación de que no podía haber sido proyectada de otra manera; y como toda gran obra de arte, muestra tanta sencillez o simplicidad (so simple) que no podemos percibir toda la perfección que encierra hasta haberla repasado repetidamente...El Salustio es uno de los volúmenes de mayor calidad producidos en cualquier país durante el siglo XVIII, aunque solamente en España pudo haber sido impreso en este particular estilo". No se ha abreviado la larga cita por la autoridad de quien la escribe, el eminente tipógrafo americano Daniel Berkeley Updique en la obra capital de la historia de la tipografia Printing Types ${ }^{1}$.

François Ambroise Didot, uno de los grandes artífices de la célebre familia de impresores, expresa la admiración que sentía por esta obra de Ibarra en los prolegómenos de la edición de Dafnis et Cloe en los siguientes términos: "Un cúmulo de gloria dificil de manifestar por lo extraordinaria, ha conseguido el eminente Joaquin Ibarra, distinguiéndose sobremanera en la excelente $\mathrm{y}$, bajo todos los aspectos, admirable edición del Salustion. Asímismo, el $\mathrm{Bu}$ lletin Officiel de los impresores de Francia del año 1910 calificaba al impresor aragonés, asentado en Madrid, como innovador por haber sido el primero que hizo conocer a los impresores el modo de satinar el papel estampado para hacer desaparecer la huella de impresión, invento con el que España ha contribuído al progreso universal de la imprenta ${ }^{2}$.

Un elogio que, pese a su significado, no se ha solido mencionar hasta ahora es la que en 1794 dedicaba al Salustio la Encyclopédie Methodique presentándolo como «una obra maestra de tipografia que ha sido consultada a menudo como un excelente modelo» ${ }^{3}$.

\section{Las menciones de responsabilidad}

Curiosamente, en la voluminosa publicación que se examina en estas páginas no consta de forma expresa que el infante don Gabriel sea el autor de las versiones de las historias de Salustio y de otros textos complementarios que enriquecen la obra, pero una serie de indicios concurrentes, 
unidos a testimonios externos, despejan cualquier posible duda sobre la autoría. La luminosa portada de carácter arquitectónico de la obra, grabada dentro de un marco entrelazado de guirnaldas, en cuya base se apoyan las efigies numismáticas de Catilina y Yugurta llevando en los extremos el fasces consular y el cuerno de la abundancia, premonitorio de la victoria romana, lleva escuetamente la siguiente leyenda: «La Conjuración de Catilina y la Guerra de Yugurta por Cayo Salustio Crispo». La leyenda se halla dividida en ocho lineas con tipos de distinto tamaño, siendo los menores los de la conjunción y de la preposición ocupando sendas lineas en una función tipográfica similar a la sintática de enlace. Pero curiosamente, ni en la portada ni en ninguna otra parte del impreso se hace mención del autor de la traducción que constituye el eje y la razón de la obra. Tampoco figura la mención de responsabilidad del prologuista ni la del autor del epílogo, aunque en esta época era normal incluirlas. El lugar y año de edición están senalados en el colofón final. No existe dedicatoria ni se inserta el privilegio del editor, anulado en 1763 por Carlos III en favor del autor, ni tampoco la tasa o precio, cuya obligatoriedad de inserción fue abolida por el mismo monarca en $1762^{4}$.

Por las primeras palabras del prólogo ya se da a entender que éste está redactado por el mismo autor del texto principal de la traducción: "Mi intento en esta traducción..." y sigue señalando siempre en primera persona el método seguido en la traducción y los objetivos perseguidos en ella. En el mismo prólogo explica también la razón de algunas de las notas en las que el de momento incógnito autor muestra una considerable erudición.

En la hoja de respeto de la biografia de Salustio, que ocupa el segundo pliego de cuatro hojas de la obra, se inserta un medallón a página entera con una efigie circundada por la leyenda "Salustius autor", de la que cuelga un marbete también circular y sombreado con la indicación de pertenencia de la medalla al «museo de S.A. Srma. el Sor. Dn. Gabriel, Infante de España». Éste es el primer indicio para atribución de autoría en favor de dicho Infante, confirmada por una sólida tradición, jalonada por una cadena de fehacientes e indiscutibles testimonios. 
El infante Don Gabriel y el Inspector Ibarra...

Sin embargo, no han faltado personas que han manifestado reticencias para aceptar que un personaje de tan alto rango se dedicase, además con buen oficio, a semejantes tareas humanistas. Así sucede con el colaborador del Diccionario de la Historia de España que en la sucinta biografía del infante, firmada con las iniciales R. E., escribe: «Fue aficionado a la cultura y con su preceptor, el humanista Francisco Pérez Bayer, tradujo —o se publicó a su nombrelas historias de Salustio, impresas por Ibarra en cuidada edición". La frase resulta incorrecta gramaticalmente e incluso históricamente pues la duda en cuestión carece de fundamento e implica la sospecha de adornarse con galas ajenas. Al contrario, las fuentes proporcionan incontestables pruebas sobre la autoría irrecusable del infante, empezando por las cartas que el citado Pérez Bayer, director de la Biblioteca Real, dirige a su paisano levantino Gregorio Mayans y Siscar, por las que conocemos el proceso que el hijo de Carlos III siguió en su esmerada y prolongada tarea de la traducción ${ }^{5}$.

A fines de 1768, Pérez Bayer comunica en el citado epistolario, dado a conocer por Jaime Moll, el comienzo de la versión del historiador romano por parte del infante. En marzo del año siguiente ofrece ya la idea de lo que será la obra, traducción con notas y reproducción de las medallas relacionadas con el texto, en las que ya estaba trabajando el también valenciano Manuel Monfort. A fines de dicho año se informa que el rey había otorgado la autorización para la impresión del trabajo y un año después, el día de Navidad de 1770, el citado bibliotecario refiere a su erudito corresponsal que se abren ya las láminas. El último día de 1771 le participa que se han tirado los dos primeros pliegos y añade: "Espero que salga la impresión magnífica, porque assí el papel como la letra y las láminas son excelentes». El 17 de octubre de 1772, Pérez Bayer escribe: "Comienzo a ver el fin de la impresión de esta obra de su alteza» y dos meses después, Gregorio Mayans le contesta dando las gracias por el ejemplar que ha recibido. Así resulta que Ibarra terminó la impresión del Salustio muy a fines de 1772 , después de un concienzudo y lento proceso, pues por esta correspondencia consta que solía declarar que no quería ni podía tirar cada semana sino dos pliegos. 


\section{El Infante Don Gabriel Antonio de Borbón (Nápoles 1752-El Escorial 1788)}

Seis varones y siete hembras, en total trece, son los hijos que tuvo Carlos III (1716-1788), todos ellos nacidos en Nápoles durante el tiempo que ciñó la corona de aquel reino. Don Gabriel fue el décimo alumbramiento de la prolífica Maria Amalia de Sajonia, muerta en el palacio del Buen Retiro a los 36 años de edad. El infante no era, pues, el segundo hijo del monarca ilustrado como dice Escolar, sino el cuarto por línea de varón, habiéndole precedido un primogénito incapacitado, el heredero de la corona española Carlos (IV) y el futuro rey de Nápoles Fernando (VI), caricaturizado no sin fundamento por Susana Sontag en El amante del volcán. Las escasas posibilidades de ceñir corona pudieron influir en que desde su infancia se aficionase a las artes y a las letras, en cuyos vericuetos estuvo rodeado de gente valiosa como el citado Pérez Bayer, Juan de Iriarte $y$ el agustino Henrique Florez.

La influencia del autor de los 51 volúmenes de la España Sagrada se deja sentir por lo menos en lo referente a las monedas coleccionadas por el infante y reproducidas en su obra aquéllas que tenían relación con el texto. En su «Desapropio" o renovación testamentaria del año 1772 , el padre Florez rogaba a sus superiores «que procuren conservar las tres colecciones de monedas, de historia natural y biblioteca, sobre cuya conservación sacó nuestro reverendísimo padre general la excomunión del Papa que tengo original». Debe de tratarse de ese documento, cuyo texto figura en tantas bibliotecas: "Hai excomunión reservada a Su Santidad...", como el que exhibe la biblioteca de la Universidad de Salamanca y se comercializa en facsímil, cuya autenticidad debe de implícar la repetición de la conminación. La estima que gozaba en la corte el sabio agustino se refleja en el hecho de que el mismo Carlos III buscó su consejo en asuntos como la adquisición de la colección formada en Paris por el caballero hispanoperuano Pedro Francisco Dávila, empobrecido en el intento, la cual constituyó el núcleo del actual Museo de Ciencias Naturales de Madrid, del que la magnanimidad de Carlos III o su sentido de la justicia le nombró su primer director ${ }^{6}$. 
Respecto a las aficiones y capacidad del infante don Gabriel, no deja de producir asombro el retrato que, como a un niño prodigio, le dedicó Manuel Monfort en 1762 (Summa Artis $X X X I, 460$ ), exuberante de símbolos y alegorías. Don Gabriel tenía entonces nueve años y su figura ocupa un pequeño espacio del centro de la mitad superior como si estuviese prisionero de las representaciones alegóricas de las ciencias y de las artes. Su equivalencia simétrica en la mitad inferior corresponde a un medallón con la leyenda en latín que evoca una defensa o concertación pública: "Dará cuenta en relación al derecho civil de todo el Código Justiniano y en la del canónico del Decreto de Graciano íntegro". En el margen inferior se sitúa la inscripción de la dedicatoria con su nombre, que concluye con las palabras Magni Parentis Magno Filio, es decir: A don Gabriel..."gran hijo de gran padre». El infante fue sometido en otras varias ocasiones a ejercicios literarios públicos de este género que servían no sólo para su lucimiento sino también del de su preceptor, sobre todo en materia de la lengua latina.

\section{La calidad de la traducción}

El historiador coetáneo Gerónimo de la Escosura escribía que la traducción de los libros de Salustio, impresos en esta obra, llamó la atención entre los sabios y especialistas de toda Europa. Para que nadie califique de lisonja tal afirmación, conviene señalar que el trabajo del infante no se limita a realizar un simple ejercicio literario más o menos brillante, sino que se reviste de unas cualidades de concisión, claridad, pureza, propiedad y elegancia, propiciadas por la capacidad insuperable de la lengua española para la traducción de los clásicos, reconocida por varios autores extranjeros que don Gabriel cita en el prólogo.

Pero aparte de la galanura literaria, el traductor se esfuerza por dar a su versión un indiscutible carácter científico en el intento de restaurar el texto auténtico del original. Explica que para ello se sirvió de códices (dos de la biblioteca del Escorial y otro de su propia colección) y de impresos de la mayor autoridad, adoptando como base 
principal un elzevirio publicado en Leyden en 1634, corrigiendo sus pasajes viciados a la luz de dichos códices antiguos, a la de pasajes paralelos del mismo Salustio, a la de otros autores coetáneos como César, Cicerón y Nepote e incluso de otros menos próximos, todos citados en el prólogo. Al final de la obra incluye un índice especial para señalar los pasajes de la citada edición elzeviriana que han sido corregidos y con qué fundamento. Don Gabriel ilustra el texto con 176 notas que ocupan 45 páginas. En ellas aclara puntos oscuros, confirma los giros y el sentido adoptado con el apoyo de textos paralelos. Explica también aquellos términos obsoletos o sin equivalencia actual como los relativos a las armas, utensilios, etc.

De la erudita pluma de Juan de Iriarte salió seguramente el más bello elogio de la traducción, circunstanciada al estilo de las monedas de ley con una doble faz: póstuma y prenatal, al mismo tiempo. Incidir en este punto sirve para remachar la autoría de la traducción en favor del infante. En su notable colaboración en Historia Ilustrada del Libro Español, María Luisa López Vidriero afirma que Pérez Bayer, director de la Real Biblioteca y preceptor del infante, revisó la traducción ${ }^{7}$. Pero esta afirmación parece más bien una conjetura, y acaso no demasiado fundada, por lo menos en un sentido exclusivo, pues los visos apuntan hacia un valimiento atribuible al citado tinerfeño, hermano del conocido escritor y fabulista Tomás. Este Juan de Iriarte, también era bibliotecario real, autor de un catálogo de obras griegas y de una Gramática Latina, escrita en verso castellano con ingeniosos recursos nemotécnicos y publicada por Pedro Marin en bella edición póstuma el año 1771, justo un par de meses después de la muerte del autor, por lo que Manuel Salvador Carmona tuvo que apresurarse para insertar en la obra una lámina con el retrato del autor con la leyenda circundante en latín: «Nació en las Islas Canarias el 18 de junio de 1702 y murió en Madrid el 10 de septiembre de 1771». El fallecido autor dedica su obra a los infantes don Gabriel y don Antonio, seguramente antiguos alumnos suyos en la lengua del Lacio, $y$, en inspiradas palabras, citadas por la mencionada autora, se pregunta: "¿Quién no admirará...la pureza, la valentía con que en boca de uno de VV.AA. oímos a Yugurta hablar 
El infante Don Gabriel y el Inspector Ibarra...

ya el idioma castellano como habló el latino en la del príncipe de la Historia Romana?» Se trata, pues, de un ingenioso elogio, póstumo por parte del autor, pero prenatal en referencia a la obra elogiada que fue publicada después de haber transcurrido más de un año desde la muerte de Iriarte, lo cual demuestra que el tinerfeño estaba al tanto de la versión que sin reservas atribuye al infante don Gabriel.

El reconocimiento más autorizado de la calidad de la versión en cuestión procede de la Real Academia de la Lengua que introdujo esta obra en el Diccionario de Autoridades. El espaldarazo de clásico que este hecho implica se vio confirmado por numerosas ediciones posteriores del texto de don Gabriel. Ya en 1804 la traducción del infante volvió a ver la luz en una edición popular en dos volúmenes de pequeño formato con una lámina y unas pocas viñetas calcográficas. En 1923, los sucesores de Hernando publicaron ambos libros de Salustio en traducción del infante don Gabriel, junto con Fragmentos de la Grande Historia en traducción de Marcelino Menéndez Pelayo. Más de dos siglos y cuarto después de su publicación primera, la traducción del hijo de Carlos III ha seguido viendo la luz en ocho ediciones de la Colección Austral.

No cabe duda de que el modélico trabajo del impresor Joaquín Ibarra apenas hubiera perdido un ápice de su mérito aunque su contenido literario no hubiera sido tan brillante, pero hay que reconocer que con ello adquiere mayor valor y esplendor por la armonización estética del continente y contenido y más teniendo en cuenta que se trata de una primera edición en estreno de auténtica gala. En memoria póstuma, no está de más recordar que el infante don Gabriel, su esposa la infanta portuguesa Ana María Victoria y un hijo de ambos recién nacido murieron en noviembre de 1788 en El Escorial, víctimas de una epidemia de viruela, pese a que tres años antes, en el mismo número de la necrológica de Ibarra, que se referirá luego, de la Gazeta, el doctor don Andrés Adame, catedrático de Vísperas de Medicina de la Universidad de Sevilla anunciaba su «Discurso médico sobre el verdadero método de curar viruelas, en fuerza del qual se convierten de malignas en benignas, 6 de confluentes en discretas». 


\section{Ibarra como Impresor del Salustio}

Sería supérfluo y pretencioso intentar dar a conocer a los lectores de una publicación como la presente, la biografía de Joaquín Ibarra y Marín (Zaragoza 1725-Madrid 1785), pero no tanto plantear la cuestión de por qué el infante don Gabriel escogió al impresor aragonés para encargarle la edición de una obra de tanta enjundia. El año 1770, momento en el que se tramita la publicación del trabajo literario de don Gabriel de Borbón, existían en la Corte 24 imprentas con 113 prensas, entre las que se contaban las famosísimas de Marín y la de Ibarra con 14 y 13 prensas respectivamente (Paredes, O.C., 60 y 68). No debía de ir muy a la zaga la imprenta de Antonio de Sancha, de cuyas prensas salieron en esta época numerosas y bellas ediciones como el Quijote de 1777 con amplios márgenes e ilustraciones y las celebradas ediciones de las obras de Cervantes de 1783 .

Durante las dos últimas décadas del reinado de Carlos III existían, por lo tanto, en Madrid varias opciones para pensar en un taller que ofreciera suficientes garantias profesionales y artísticas. La elección, sin embargo, recayó en Joaquín Ibarra que, pese a no haber llegado todavía a declarar la plenitud de su genio, había demostrado poseer un sentido innato de la belleza tipográfica y un instinto de bibliofilo en ediciones como la de los Historiadores Primitivos de las Indias Occidentales, (1749) con tiradas en papel marca y marquilla, y la del Parnaso Español. En la edición del Quijote de 1771, con 36 láminas calcográficas dibujadas por Camarón y grabadas por Manuel Monfort, Ibarra ostenta ya el título de impresor de Cámara de S. M., lo cual pudo ser decisivo en que el encargo recayese en él.

Pese a todo, el impresor con su taller situado en la calle de la Gorguera, en el número 11 de la que actualmente se denomina Núñez de Arce, en cuya finca se lee una lápida conmemorativa, no había destapado todavía el tarro de sus mejores esencias. Lo hizo con sus tres obras señeras, la primera en el orden cronológico y la más lograda en el técnico y artístico fue precisamente la que nos ocupa. Las otras dos, publicadas en 1780 , siguiendo un orden de prelación, son el Quixote en cuatro volúmenes y la Historia General de España de Mariana en dos. 
El infante Don Gabriel y el Inspector Ibarra...

La inmortal obra de Cervantes figura como "Nueva edición corregida por la Real Academia Española" con el fin de distinguirla de la de 1771 . Esta nueva edición, en $4 .^{\circ}$ mayor, que se abre en las dos primeras páginas con la Licencia de Su Majestad, firmada por Manuel de Lardizabal y Uribe, se suele calificar como la edición de la Real Academia y está precedida por un prólogo impersonal o colectivo de la docta corporación, la cual, además, cuidó de su texto y vigiló su impresión. En ella quedó establecido el título definitivo de la obra como El Ingenioso Hidalgo Don Quixote de la Mancha en lugar de Vida y Hechos de...como se solían titular las ediciones anteriores. Otra particularidad en cuanto a su artífice es que ahora ya figura además como impresor de la Real Academia y pronto añadiría el tercer título de impresor del arzobispo primado que consta en la edición del llamado Breviario Mozárabe que repite la edición del Breviarum Gothicum, impreso por orden de Cisneros con las normas litúrgicas del rito mozárabe, establecidas en el IV Concilio de Toledo (633) y restablecidas para la capilla de la catedral de Toledo. Esta última edición, que se abre con una lámina dibujada por Maella y abierta por el mayor y mejor de los Carmona presentando a San Isidoro en actitud de escribir junto a los demás obispos asistentes, fue encargada por el famoso cardenal Francisco Antonio de Lorenzana, autor, editor y coleccionista de documentos y libros de valor inapreciable, quien por sus ideas regalistas no podía dejar de mirar por la restauración del antiguo rito hispano. Los tres títulos del impresor aragonés eran recordados en la amplia reseña necrológica que publicó la Gazeta de Madrid el 18 de noviembre de 1785, cinco días después de su muerte, porque el hecho "merece noticiarse al público a causa de hacer este sujeto época en los anales tipográficos de España».

La edición de la Historia General de España, 2 vols. en folio, fue realizada bajo la dirección de la Biblioteca Real. Originariamente escrita en latín, fue traducida por su mismo autor jesuita en la época de Felipe II y editada en varias ocasiones. En estricta justicia merece el tratamiento de primera historia sistemática de España, en contraste con otras obras históricas anteriores menos sistematizadas por su carácter de crónica. En cierto modo se la puede considerar 
también como una edición oficial, apoyada por el erario público, sin escatimar medios en su realización. De esta edición, como de la del Salustio, se tiraron ejemplares especiales destinados a los miembros de la familia real y a otras personalidades de alcurnia.

De las lineas precedentes se desprende que Joaquín Ibarra fue un impresor favorecido por las instancias oficiales. No careció de medios por ello para realizar sus exquisitos trabajos, al actuar bajo la sombra benéfica del trono real. Algunos eruditos suelen contraponer a su figura la de Antonio de Sancha como más meritoria, pues sin ayudas realizó una importante labor en todas las facetas del arte de la edición, incluyendo la de la encuadernación, de la que el impresor aragonés no parece dejar huellas reconocibles. Quizás las cosas sean así, pero habría que dilucidar si esa predilección no había sido ganada a pulso por Ibarra y, sobre todo, reconocer que desde una perspectiva de más de dos siglos quién ha sido más encumbrado por los laureles de la historia, aunque Sancha, distinguido con una calle con su nombre en Madrid, no así Ibarra, no le iba muy a la zaga.

\section{Número de ejemplares de tirada}

A falta de un inventario minucioso, se presume que de las prensas de Joaquín Ibarra pudieron salir más de dos mil ediciones. Después de unos años de aprendizaje con su hermano Manuel en la imprenta de la universidad de Cervera, en 1742 se trasladó a Madrid para trabajar en el taller de su tio materno Antonio Marín y en 1753 se independizó abriendo su propio taller con tres prensas. Dos años después tenía capacidad para hacer frente a un pedido de 40.000 Catones como el que le hizo la Hermandad de San Jerónimo de Mercaderes de Libros de Madrid. Tiradas similares solían alcanzar en este tiempo las impresiones de catecismos, de las que no se conserva ni un solo ejemplar.

Con la documentación existente en el archivo de la citada Hermandad, Paredes deduce algunas conclusiones sobre el número de tirada que alcanzaban las ediciones en esta época. Aunque en 1655, la Hermandad de San Jerónimo llegó a 
El infante Don Gabriel y el Inspector Ibarra...

vender en menos de un año siete mil Oratorios de fray Luis de Granada (hoy titulado Libro de Oración y Meditación), tales tiradas, según Paredes, eran excepcionales. En el mencionado archivo hay constancia de 16 ediciones realizadas entre 1735 y 1819 , cuya tirada media es de 2.000 ejemplares, con un número mínimo de 1.500 y máximo de 3.000. Naturalmente, el número de ejemplares impresos dependía, como ahora, de la previsible demanda, condicionada por la naturaleza de la obra y de su contenido y destino. A tenor de ello, la Recopilación de las Leyes de los Reynos de Indias en su primera edición de 1681, impresa en Madrid por Julián de Paredes, por ejemplo, alcanzó una tirada de 3.500 ejemplares ${ }^{8}$.

Sin desestimar otros criterios como la calidad de la edición, el formato, etc., la conservación de ejemplares tiene una relación directa con la tirada de impresión e inversa con la antigüedad ${ }^{9}$. La edición del Quijote de la Real Academia, impresa por Ibarra, tuvo, según el Palau, un alcance de 1600 ejemplares. Dos siglos después, la oferta de dicha obra en el mercado del libro de lance es menos frecuente que la del Salustio, obra de igual o mayor antigüedad y del mismo impresor, de la que se realizan todavía transacciones frecuentes. En concreto, en la «III Feria Internacional del libro antiguo", celebrada en Madrid en 1994, hubo una oferta de cuatro ejemplares de la misma, dos de ellas procedentes del extranjero. En 1995, se han realizado igualmente una transacción en una subasta en Madrid y alguna más en librería; cierto librero de la capital asegura asimismo que en la actualidad posee una oferta de varios ejemplares de distinto precio. El ejemplar más caro de la mencionada feria se ofrecía por 1.025 .000 pesetas, el más barato se cerró en la referida subasta por 500.000 pesetas. Son precios relativamente moderados en comparación de la excepcional cotización de seis millones de pesetas que el citado Quijote de 1780 alcanzó, según la prensa, en una subasta de New York a fines de 1995, pero se debió de tratar de un ejemplar especial ornada de unos atributos excepcionales, pues por menos de la sexta parte se puede adquirir todavía algún ejemplar con una modesta encuadernación en piel y guardas de papel. Pese a todo, una pintura singular $u$ otra obra destacada en cualquiera de 
las ramas del arte de la misma época, producida por un esfuerzo y una inspiración similares, si no menor, alcanzaría cotizaciones muy superiores. Es una muestra del injusto principio de que la escasez confiere a los productos un precio, no un valor, superior y la copiosidad de la oferta que de ningún modo degrada el objeto, reduce su cotización.

La señalada frecuencia de oferta de esta obra incomparable muestra, sin lugar a dudas, el elevado número de ejemplares de su edición. La aparición de ofertas procedentes del extranjero indica, además, que el libro llegó a tener una amplia difusión internacional, confirmado también por los elogios que la obra mereció en varios países del extranjero y por el epistolario de Pérez Bayer con Mayans al señalar que se estaban enviando ejemplares a las principales cortes europeas. Esta última expresión hay que entenderla en un sentido amplio, pues Ruiz Lasala desentraña que uno de los beneficiarios del envío fue el embajador americano en París, Benjamin Franklin, que correspondió enviando un ejemplar de las Actas del Congreso de aquel joven país. Otro de los beneficiarios del envío al extranjero fue José Nicolás de Azara, comisionado a Roma por Carlos III con objeto de conseguir la supresión de la Compañía de Jesús, quien en su correspondencia con el ministro Manuel de Roda se interesa por la edición del Salustio, que califica de admirable, e informa que acaba de recibir. Azara dice que hace de ella un "extracto" para cierta gaceta, y a manera de agradecimiento envía «un pequeño fragmento de Tito Livio, inédito, que se ha hallado en la Vaticana, el cual trata de la guerra de Sertorio y se está imprimiendo en una disertación no mala» ${ }^{10}$. Sin duda, el infante don Gabriel se sentiría orgulloso de presentar la muestra de su trabajo a los personajes e instituciones extranjeras y a los del propio reino y los cortesanos que no se vieron favorecidos por el obsequio se apresurarían ellos mismos a adquirir, acaso ocultamente, un ejemplar para no quedar en entredicho por no haber sido objeto de una distinción personal.

De acuerdo con estas reflexiones y datos no cabe dudar de que la edición de La Conjuración de Catilina y la Guerra de Yugurta, estampada por el maestro aragonés, tuvo que imprimirse en una cantidad de ejemplares bastante superior a la normal en la época, doblando quizás el número de 
dos mil, que constituía la tirada media, se incluyese o no la especial de 120 ejemplares, o dejándola cuando menos en los 3.500 de la citada Recopilación que también fue señalada por su destino de amplia difusión, en el caso de forma privativa en el Nuevo Mundo y restringida a él.

\section{El papel de la edición}

En una edición de gran lujo, los susceptibles bibliófilos requieren la confección de un papel especial, fabricado ex profeso y una letrería igualmente propia. En realidad, en aquellos tiempos de fabricación manual y artesana, la cantidad de papel necesaria para una edición del volumen y tirada del Salustio - unos 170.000 metros cuadrados en un número tres veces superior de pliegos- tenía que proceder de un encargo especial. Por eso, más que el hecho de la fabricación especial, interesa el de la calidad del producto. En la referida carta del 25 de diciembre de 1770, Pérez Bayer escribe al respecto: "Aunque no tenemos aún copia (acopio) de papel, porque no se ha podido este año trabajar en Capellades por falta de agua, pero las muestras que nos han enviado son como lo más exquisito de Olanda".

La sequía, al parecer viejo problema español, debió de estar ya en vias de solución porque seis días después en el socorrido epistolario se elogia la excelencia del papel y se dice que ya se habían tirado los dos primeros pliegos de la obra. A fuer de ajustar detalles, hay que decir que el mencionado soporte de impresión no fue fabricado en Capellades, sino en la vecina villa barcelonesa de Pobla de Claramunt, tal como indica la marca de agua. En el libro, cada pliego constituye un cuadernillo de cuatro hojas y en ellas se alternan en direcciones opuestas a causa del plegado del pliego, la filigrana de una torre, no de un castillo, como se ha escrito, y la leyenda Fco. Guarro.

La casa Guarro, cuyo nombre subsiste en forma de sociedad anónima y estampa la prosapia de su antigüedad secular en las filigranas de actuales ediciones de gran bibliofilia como en el Quijote ilustrado por el académico Teodoro Miciano, cuyas planchas custodia la Academia de Bellas Artes. Lo mismo ocurrió con la tirada de 60 ejemplares 
de la edición facsimil de la obra que nos ocupa, realizada en 1992, quizás discutible por su reducido número que tuvo que repercutir en un alto costo relativo cuando todavía no es imposible adquirir ejemplares originales.

En concreto, el papel de esta impresión es de color blanco, con cierta tonalidad marfileña, y verjurado, mas no con puntos, sino con desvanecidas lineas verticales contínuas. $\mathrm{Su}$ gramaje mantiene el cuerpo conveniente para sus considerables dimensiones y el grado de opacidad suficiente para impedir el trasluz de grabados y punzones, cuya fijación logra evitar la menor huella. Esta cualidad es obtenida mediante la técnica del satinado, cuya novedad constituye una aportación de Ibarra al arte de la impresión y que, frente a la laberíntica descripción de algún autor, está sencillamente explicada en la referida nota póstuma de la $G a$ zeta: "Introduxo entre nosotros el uso de pasar por el tórculo los pliegos impresos para quitar toda huella de la prensa, las arrugas del batido (que nunca puede ser igual) y darles lustre, debiéndosele en buena parte el buen gusto que han imitado y reyna entre los impresores españoles».

\section{El secreto de las tintas}

En el artículo que la monumental obra biográfica francesa dirigida por Michaud dedica al impresor aragonés se dice que sus producciones en la imprenta de Madrid son conocidas por toda Europa y solicitadas por los "amateurs". De ellas destaca como obras tipográficas maestras el Quijote y la traducción del Salustio. Dice que parece haber sido Ibarra el que introdujo en España el uso de satinar (lisser) el papel impreso, extremo que ya se ha confirmado en el epígrafe anterior, y afirma que también se le ha atribuído a él el descubrimiento de una tinta cuyo espesor aumentaba o disminuía a voluntad. El autor de dicho artículo biográfico muestra cierto excepticismo ante esta afirmación, por lo menos teniendo en cuenta la composición de la tinta de imprimir en Francia; pero señala que en España cada impresor producía el líquido impresorio para su propio consumo y añade que quizás se deba a ello la belleza y solidez de las tintas españolas que han quedado de este modo inte- 
El infante Don Gabriel y el Inspector Ibarra...

gradas como parte del conjunto del arte de imprimir y no se han convertido en un objeto de comercio. El biógrafo francés se hace eco también de la creencia de que el impresor aragonés solía mezclar en su tinta una pizca de azul de Prusia ${ }^{11}$.

Dicha mezcla podría estar integrada acaso en la fórmula especial y secreta que se rumoreaba que tenía Joaquín Ibarra para conseguir aquellos barnices de calidad y brillantez excepcionales. Es posible que, vistos los resultados, el impresor del Salustio utilizase igualmente un componente especial de fijación o de adherencia de la tinta para ofrecer la versatilidad admirable que lucen las letras, sobre todo las de naturaleza de palo y también la "V" y la "S" larga que Ibarra introduce en lugar de las tradicionales "u» y "F", asícomo en los signos ortográficos - emplea el acento grave en lugar del agudo- que tiene la configuración de un agudísimo triangulo isósceles, rematado en una delgada punta, como amenazando pinchar, pero nítida al estilo de un finísimo cabezal diamantino o de buril.

Esta observación propende a resaltar la virtud de la nitidez del barniz (así lo llamaban ellos) empleado en la impresión del Salustio, el cual, mediante el temple y espesor adecuados, logra destacar los tipos sobre el fondo del papel y obtener unos caracteres limpios, sin bordes grasientos y sin corrimientos fuera de los cuerpos. A esto último conspiraba uno de los logros destacados en la citada nota necrológica de la Gazeta en la regulación de la composición de la tinta de acuerdo con la exigencia de los cambios térmicos de la climatología.

\section{La Letrería}

Los tipos de letra que usa Ibarra en su comentada edición de 1772 son variados en razón de la acomodación especifica que requieren las distintas partes de que se compone la obra. El objeto formal de ésta se cifraba en la versión española en cuanto texto principal y razón de las demás partes integrantes. Los tipos del texto de dicha versión obtienen por ello la mejor consideración en lo referente a cíceros, originalidad y elegancia con una cursiva inclinada de unos 
14 puntos de cuerpo, en armonía con el gran formato del libro, y una lograda claridad de lectura, incluyendo la utilización de lingotes o regletas para el interlineado y evitar así, con ajustados espacios, confundirse al bajar la vista de derecha a izquierda a otra linea. De la misma familia, pero como de unos doce puntos, es la letrería del prólogo, diseñada, igual que la anterior, por el académico de Bellas Artes Antonio Espinosa de los Monteros, el primero de los talladores que con su Muestra de los caracteres, impreso en 1771, contribuyó, como buen maestro, a dar esplendor a la letrería española y a desligarla de la dependencia extranjera.

En el pliego o cuadernillo de cuatro hojas, señalado con la signatura ${ }^{* *}$, que contiene la Vida de Salustio, encontramos una fundición redonda, más acorde con el espíritu romano que personifica el historiador. En este texto, las interpolaciones para citas, informaciones complementarias, etc. se hacen con letra cursiva al estilo de las ediciones modernas, del mismo modo que en las demás partes de la edición se asocian siempre con tipos de distinto carácter. Jaime Moll califica esta letra de clara, muy legible, con equilibrio de perfiles y gruesos, con sensación de fuerza en su expresión. Y hace votos por su restauración pese a que se le puede objetar que, aun con períodos de sequía, ha llovido mucho desde entonces.

El tipo de letra de la versión castellana podría tener una relación de proporcionalidad con el del prólogo como el de la Vida de Salustio podría manifestar una correspondencia de afinidad con el texto del original latino. La traducción y el prólogo mantienen cierta distinción jerárquica, pero se emparentan en la forma tipográfica. El tipo del texto primigenio en lengua latina, a su vez, se relaciona en buena lógica con el de la vida de su autor romano. Se trata de una letra redonda de menor cuerpo, ocho puntos, - el texto latino no era objetivo de la publicación, sino referencia-, con la firmeza, orden y agilidad de una cohorte en las batallas que describe.

Finalmente está la letra redonda, de seis puntos, con muy frecuentes interpolaciones en cursiva, de las notas, la misma que se emplea en el tratado sobre la lengua de los fenices, hablada en Leptis por los súbditos de Yugurta, 
y también en los apéndices, la cual provenía de Inglaterra, fundida por el célebre William Caslon.

De esta manera se producía no solamente una adaptación y harmonía de la forma y la materia, el contenido y el continente, sino también una jerarquización entre ambos extremos manifestada por el escalón de cíceros o puntos que otorgaba variedad y contribuía a romper la monotonía frecuente en impresiones de similar formato. Pero es en la confección de las planas o páginas, es decir, en la imposición, donde el impresor debe demostrar fundamentalmente su habilidad y dominio de los secretos del noble arte de la impresión.

\section{Arquitectura tipográfica de la plana}

Para lograr una buena arquitectura tipográfica tanto de las páginas consideradas aisladamente como de la compaginación del conjunto, por el carácter repetitivo de las planas, hace falta algo más que la provisión de buenos y adecuados elementos materiales. En esta cuestión, como en cualquier otra relacionada con la arquitectura, el diseño y los planos dirigen la realización del proyecto. En ello precisamente despunta de forma especial el genio impresor del maestro de la imprenta de la calle de la Gorguera, pues la estructura de cada página frente al reto de la proporcionalidad de dos textos y la compaginación del conjunto suscitan verdadera admiración. Ibarra se vio precisado a acoplar de forma armónica dos textos de diferente fisonomía: La versión castellana, eje de la publicación, con derecho a un tratamiento de mayor relieve, y el original latino con una función complementaria.

La anchura de 13 centímetros de la caja de impresión era la adecuada para el indicado tipo de letra de la versión, pero no así para el más pequeño del texto latino que hubiera formado una linea demasiado larga y estrecha para la dimensión de la caja. La solución lógica a esta dificultad consistió en dividir en dos columnas dicho original situándolo en la parte inferior de la caja y conseguir, de forma admirable y sin la menor fisura, la proporcionalidad de 1 a 1,6 entre ambos textos, cifrada en la relación de la parte menor con la mavor como la de ésta con la suma de las dos v aue 
Gutenberg y los grandes maestros de la impresión trataron de aplicar con la denominación de la regla áurea o divina. Las 20 lineas de la versión y las 12 del texto original establecen la proporción de 1:1,6 y la suma de las dos partes $=32$ y su relación con la parte mayor $20(32: 20)$ se resuelve en la misma relación matemática de 1:1,6. Pero lo que resulta más admirable es que Ibarra consigue mantener invariable página tras página dicha relación, incluso en la primera y última que reducen el número de líneas y todo ello sin espaciados irregulares ni apreturas perceptibles.

Con el papel especial como soporte, con el suave realce de las tintas, con la graciosa y serena originalidad de la letrería, con la armoniosa imposición tipográfica, con los generosos márgenes, con la limpia e intachable impresión, aparte de todos los elementos ornamentales e ilustrativos, Joaquín Ibarra consigue plasmar unas páginas alegres, armoniosas, plenas de luminosidad y de placidez como un jardin cortesano de simétricas y amplias avenidas. El libro abierto en su perspectiva de doble página constituye un verdadero regalo para los ojos y reposo y sosiego para el lector.

\section{Contextura interna}

El libro impreso por Ibarra está formado por cuadernillos de cuatro hojas que mantienen la signatura al estilo antiguo para el orden de alzado de los pliegos. El primer cuadernillo está ocupado por el prólogo y señalado por un * al pie de la primera hoja y $* 2$ al de la segunda, con las otras dos hojas en blanco, pues ya no existe posibilidad de error de plegado. El segundo cuadernillo, que se destina a la biografia de Salustio, está marcado por $* *$ y **2. Los cuadernillos del texto principal y de los apéndices están signados en las dos primeras hojas por las letras mayúsculas del alfabeto latino, por tanto $\sin \mathrm{J}$ ni W, incorporando a la segunda hoja el número 2 (A, A2). Las letras se duplican o triplican al acabar la serie, siendo la última la señalada con DDD, que viene a corresponder por lo que se ha dicho a la primera y única señalada por dichas tres letras. Pero a partir de 
El infante Don Gabriel y el Inspector Ibarra...

la signatura A, impresa en el lugar tradicional del margen inferior a la derecha, la obra lleva también en el margen superior derecho una paginación arábiga correlativa que va del 1 al 395 de la última página, rematada por un bellísimo florón de Carmona iunior.

\section{Apéndices y complementos}

En la paginación general se incluyen las extensas notas aclaratorias correspondientes a los dos textos de la rebelión de Catilina y de la guerra yugurtina (pp. 289-334). Luego viene el ensayo sobre el alfabeto o lengua de los fenices (fenicios), que se considera dialecto de la lengua hebrea (pp.337-378). De forma expresa se declara que el autor del mismo fue otra persona distinta del infante don Gabriel, pues lleva la advertencia de que se compuso en obsequio del autor de la traducción y para satisfacer sus deseos de instruirse en lo más arcano de esta literatura, y éste, don Gabriel, fue quien, después de haberlo examinado, lo mandó imprimir a continuación de los textos de su versión y del original latino.

La clara atribución del ensayo a otro autor, confirma una vez más la honradez del infante don Gabriel de no querer vestirse con galas ajenas. Tampoco existe en la obra constancia expresa del autor del mismo, pero se puede asegurar con certeza que fue Francisco Pérez Bayer, uno de los preceptores del infante don Gabriel, que estaban dirigidos por Joaquín de Zúñiga, duque de Béjar, ayo del príncipe de Asturias y de sus hermanos por real nombramiento de Carlos III. Bastaría señalar como prueba de dicha atribución la obra De Numis hebraeo-samaritanis que Bayer publicó en 1781 en la oficina valenciana de Benito Monfort, donde amplía el tema tratado en el ensayo del Salustio. El trabajo de este brillante impresor valenciano en esta publicación es calificado de deslumbrante por María Luisa López Vidriero, quien reproduce dos calcografias de la misma, una de ellas un retrato de Carlos III, en cuya paráfrasis la citada autora y actual directora de la Biblioteca del Palacio Real comete un desliz que bien le hubiera podido costar su cargo en la biblioteca real durante el antiguo régimen: 
Se trata de la leyenda del pie de dicha calgografia referida al buen monarca de la Ilustración: Et veteres revocavit artes que la autora citada por cierta sombra del original leyó y transcribió en la glosa: Et veteres revocant artes, cambiando el sentido de la frase "y renovó las viejas artes" por el de "y los viejos renuevan las artes".

A continuación del ensayo, la obra incorpora unos apéndices que en una primera impresión pueden parecer ajenos al tema, pero conspiran como focos de luz a iluminar el argumento de la tragedia. El primer apéndice señala los pasajes en los que el texto de la edición corrige los del elzevirio del año 1634 (pp. 379-89). Sigue un amplio texto con el título de Cosas Notables que viene a ser un índice analítico de materias (pp. 380-393). Luego viene un elenco de las magistraturas urbanas y de los mandos militares con el significado y las funciones respectivas en la política gubernativa y en el ejército. Y, por fin, una relación de leyes y senatusconsultos, entre ellos contra el cohecho y el soborno, de que Catilina acusaba a los magistrados, y contra la conjuración frente a la república, cargo que pesaba sobre Lucio Sergio Catilina.

La minuciosidad de esta relación precedente se justifica no sólo por señalar el sentido complementario de las referidas partes, sino también porque la obra carece de un índice general sistemático. Aliquando dormitat Homerus? No necesariamente, porque en aquellos tiempos todavía era costumbre bastante general no insertar dicho índice cuando se agregaba uno analítico con el título de Cosas, Tablas, etc., como se agrega en el caso y, además, uno muy minucioso.

\section{Las ilustraciones calcográficas}

Se utiliza el término de Ilustraciones en lugar de láminas, estampas, iconografia $u$ otros equivalentes, con la intención de subrayar la proyección de las mismas hacia la función ilustrativa del libro y esclarecimiento del texto, principio irrenunciable en la estética, e incluso en la ética, de componer y decorar libros. El buril y el agua fuerte no vacilan en mostrar su ambición de acariciar e infundir sentido a los rincones adecuados del papel con viñetas, florones, 
amorcillos y putti, capitales, colofones, etc., en cuyo diseño y apertura compiten los más destacados creadores de aquella época, calificada por el especialista Carrete Parrondo como de triunfo de la estampa ilustrada: Manuel Monfort, Mariano Salvador Maella, los hermanos Salvador Carmona, Manuel y Juan Antonio, que también firma como Carmona iunior, José Joaquín Fabregat como dibujantes y grabadores; el geógrafo de S. M., Juan de la Cruz, que compone y graba el mapa del Mediterráneo con la Numidia, con posiciones geográficas bastante inexactas. En calidad de grabadores intervienen Joaquín Ballester, Francisco Assensio, Jerónimo Antonio Gil, autor de la letrería del Quijote de 1780, y Francisco Muntaner. También aportan sus diseños Isidoro Carnizero y Fernando Selma ${ }^{12}$.

La obra contiene nueve láminas fuera de texto, cuya descripción no permiten los límites ni el objeto de este trabajo. Pero por su patetismo y sentido histórico merece dedicar unas lineas a la ilustración de la batalla de Pistoya, reproducida por Summa Artis y por la citada obra dirigida por Hipólito Escolar, aunque sin identificarla ni explicarla. Fue ideada por Maella y abierta por Manuel Salvador Carmona, para cuya comprensión conviene reseñar sus inmediatos antecedentes en lo que respecta a la arenga previa que Salustio pone en boca de Catilina, comparable en belleza y valor persuasivo a las que Curcio Rufo pone en boca de Alejandro Magno o Julio César en la suya propia, y que casi impulsa al lector de hoy a inscribirse en las filas de su ejército. Por un lado se pone de relieve la corrupción, la tiránica opresión y la indignidad de los magistrados romanos. Por el otro, se presenta a Catilina, cuya imagen denostada nos trasmitió su enemigo Cicerón, blandiendo el emblema de la justicia que él y su gente persiguen. Une su suerte a la de sus soldados en el triunfo y en la gloria de los vencedores o, en caso de derrota, promete que su sangre se fundirá con la de todos los suyos y juntos cerrarán los ojos para no seguir viendo ya más la exaltación de tanta ignominia.

La escena describe este último momento patético. $\mathrm{Al}$ fondo, un soldado permanece impávido, al estilo del legendario centinela pompeyano, en la custodia de los caballos que Catilina le había encomendado al mandar apearse a 
sus soldados para enfrentarse a pie con el ejército enemigo. Han caído ya todos sus hombres y Catilina, solo, se abre paso, espada en mano, entre los cuerpos de sus soldados abatidos en tierra, con el fin de enfrentarse, con arrojo suicida, a los componentes de una cohorte, en cuya mirada se refleja el encono y la angustia de la batalla, mientras que el rostro de Catilina queda velado por los enemigos que le rodean como presagio de su destino inmediato de cerrar los ojos a la ignominia. Es dificil encontrar una ilustración más expresiva de la tragedia.

\section{Formato y márgenes}

La regla áurea de la proporción en la estética gráfica, exigible en ediciones de alto nivel, tiene una aplicación particular en la relación del formato y de los márgenes. La proporción de 1:1,6 y sus múltiplos de 5:8 ó de 15:24, para acercarnos a uno más usual, es la norma impuesta por la praxis de los grandes impresores en la proporcionalidad de las dimensiones de la caja o molde impreso y de la página o formato. Sin embargo, hay ediciones de gran lujo o tiradas especiales de algunos ejemplares, como ocurre con el que es objeto de estas reflexiones, en los que se rebasan tales medidas y proporciones como cuando las reinas lucían en las grandes solemnidades blancos mantos de armiño con cola.

Siguiendo el criterio más aceptado entre los impresores, el margen inferior o falda de la edición de Ibarra es mayor que el superior en una proporción aproximada de 5:8 (1:1,6 $x$ 5), sin poder ser precisado con exactitud por el corte variable a que la haya sometido el encuadernador. En los márgenes laterales, sin embargo, la anchura del margen externo es mayor que la del interno o de costura, en la que no cabe aplicar la citada regla porque la unidad visual de percepción del libro es la doble página y en ella se unen ambos márgenes interiores. Por esta razón, dichos márgenes no admiten unas medidas fijas, pues la merma visual producida por la costura depende del número de páginas y los libros gruesos producen una redución visual mayor. 
El infante Don Gabriel y el Inspector Ibarra...

\section{La técnica de la estampación calcográfica}

Joaquín Ibarra fue un innovador en lo relativo a la estampación calcográfica. Su aportación consistió en un procedimiento para eliminar el rebordeo o bajorrelieve que produce la estampación de la plancha de grabado. La presencia de dicho reborde, en contra de una creencia bastante extendida, no es muestra segura de que la estampa sea calcográfica. Recientemente se ofrecían en el Rastro madrileño unas láminas de la serie de tauromaquia de Goya con dicho reborde que no eran más que burdas fotocopias. Al contrario, en las calcografias de Ibarra, incluso en las de menor tamaño, no existe tal reborde, lo cual se debe a que la plancha de cobre tenía unas medidas que rebasaban el papel y dejaba la huella fuera de la página o, mejor, la plisaba toda, sacando el borde fuera.

En su estimable trabajo, Jaime Moll escribe que las láminas y los demás elementos calcográficos del Salustio se estamparon en el taller de Matías Ricart y expresa su extrañeza de que un taller tan bien dotado como el de Ibarra, en el que se llegaron a imprimir tantos libros con láminas calcográficas, no incluyese por lo menos un tórculo. El citado bibliógrafo se apoya a este respecto en la rama de Contaduría del Archivo del Infante Don Gabriel, conservado en el Archivo del Patrimonio Nacional, donde figura una factura en favor del referido taller por la estampación de dichas calcografias y añade el argumento de que en dos inventarios de utensilios de la imprenta, uno de ellos amplio y minucioso del año 1787 en el que se hace mención de veinte prensas y no se menciona ni un solo tórculo ${ }^{13}$.

Pese a todo, no deja de haber argumentos contrapuestos a los aducidos por el citado autor. Joaquín Ibarra fue un empresario innovador y dos de sus aportaciones novedosas se realizan precisamente en el campo de la aplicación del tórculo. Una de ellas consiste en la introducción del plisado de los impresos, cuya técnica consistía, como ya se ha dicho, en pasarlos por el tórculo. Entonces se hace duro pensar que el brillante impresor acudiese a plisar cada pliego a un taller ajeno. Se añade a ello que el artista zaragozano introdujo el sistema de evitar el rebordeo en los elementos calcográficos, lo cual no resultaría nada cómodo sin disponer 
tórculos propios. En resumen, a despecho de las apariencias, cabe presumir que Ibarra necesitaba tórculos, tenía sobrada capacidad económica para adquirirlos y suficiente personal para su manipulado.

El hecho de que en los dos inventarios, tan minuciosos, se hable de prensas y no de tórculos resulta ciertamente sorprendente, pero en las relaciones de las imprentas de la época, como se desprende del estudio citado de Paredes Alonso, se hace mérito de las prensas, pero con mucha frecuencia se dejan de mencionar los tórculos pese a que se hace dificil suponer que careciesen de ellos como si su explotación perteneciese a otra rama industrial. ¿Podría ser que el fabricante de dicho artefacto mantuviese la propiedad y lo alquilase a las imprentas en una especie de leasing?

A mayor abundamiento, cabe añadir una consideración de la nota necrológica de la Gazeta de 1785 en la que se afirma que el recientemente fallecido impresor aragonés tenía empleadas regularmente al día más de cien personas -entonces estaba lejos todavía el contrato fijo y permanentey proporcionaba, además, ocupación, se entiende que fuera, "a los fundidores, fabricantes de papel y enquadernadores". Habría que dejar opinar a los profesionales sobre si cien empleados no serían demasiados para veinte prensas, de no tener otros artefactos, pero en la frase de la referida nota, escrita de primera mano con conocimiento de causa, no se dice que entre los distintos profesionales a los que se daba trabajo fuera del taller se incluyesen los grabadores. Esto no quiere decir que en ocasiones más o menos excepcionales no lo pudiera hacer forzado por las apreturas circunstanciales de trabajos de mucha envergadura. El hecho de que Ibarra resignase en otro taller la apertura de las láminas del Salustio, seguramente sólo una parte de ellas, abona la presunción de la amplitud de tirada que tuvo que tener la edición.

\section{La encuadernación}

En el catálogo de la exposición La Encuadernación Artística Española Actual, organizada por la Biblioteca Na- 
El infante Don Gabriel y el Inspector Ibarra...

cional en 1986, siendo su comisario Manuel Carrión, figuraban dos ejemplares de nuestro Salustio encuadernados recientemente por Antolín Palomino. A primera vista produce cierta extrañeza el hecho de que sus propietarios, nada ignaros en cuestiones de bibliofilia, sino al contrario muy reconocidos, hubiesen optado por una encuadernación nueva, por supuesto, muy brillante, desechando la de la época, con el consiguiente tributo de reducción de márgenes por lo menos en medio centímetro y de la pérdida del bouquet de lo añejo. La extrañeza se despeja al considerar que el examen de un número plural de ejemplares ha dado como resultado la existencia de varios tipos de encuadernación de la época -es peligroso hablar de encuadernación original-. Según dice el citado comisario en la introducción de dicho catálogo, hasta el siglo XIX la encuadernación servía para cubrir un libro que estaba hecho para leer. A partir de entonces servía para ser visto. Esa venía a ser la regla general, pero en los libros antiguos se encuentran bellísimas encuadernaciones, escuelas y artistas conocidos de encuadernadores que en algunos casos afectaban a ediciones enteras.

La encuadernación artística de lujo y de gran lujo ha existido siempre, antes y después de la imprenta, pero sólo estaba al alcance de poderosas personalidades. Las que en su época cubrieron y engalanaron el libro del Salustio comprenden varias categorías, aunque todas en plena piel de unos 60 × 40 centímetros de superficie, pero de distinta calidad. La más sencilla lleva como única decoración una rueda dorada en los bordes, sin hierros en el lomo, con seis nervios exigidos por el volumen y guardas de papel marmol. Mayor número de ejemplares se descubren con una encuadernación de lujo en tafilete o marroquí, que compagina riqueza y austeridad dentro de un ámbito de gran dignidad. Y otra tercera categoría de gran lujo de exquisita hechura. Y por supuesto, el derroche de la encuadernación de la tirada especial limitada, que pudo ser obra de Sancha en sus elucubraciones más frondosas.

En la encuadernación de lujo que parece más general, la ornamentación descansa principalmente sobre ruedas doradas. Una de ellas, enmarcada entre dobles lineas de filetes adorna las tapas. La misma rueda, con un solo filete interno, 
bordeado con una linea dentada, embellece los contracantos. Curiosamente, los estrechos cantos de la dobladura de las tapas llevan también una rueda dorada. El lomo cuajado incorpora seis nervios dorados, cuyos entrenervios lucen una margarita central, circulitos y rocallas en cada ángulo. Los cortes son dorados y las guardas de moaré.

\section{Particularidades de cada ejemplar}

Las características expuestas se han deducido como comunes de varios ejemplares examinados, pero en ellos se advierten, además, ciertas diferencias de impresión más o menos perceptibles que merecen ser resaltadas para aviso de navegantes profesionales o aficionados en una edición de tan alta calificación ${ }^{14}$.

Las antiguas ediciones de procedimiento artesanal se podrían comparar con un parto múltiple y, más en concreto, con un parto de gemelos; es decir, un parto monoovular en el que las gestaciones son como copias fieles entre sí (en los vivientes suelen ser incluso del mismo sexo), porque proceden de moldes comunes, pero sin llegar a convergir en clones, pues admiten ciertas peculiarides a causa de que los moldes no son absolutamente inertes o inamovibles y, a lo largo de la edición pueden sufrir variantes tanto en la calidad y forma de los materiales como en la de la misma hechura del trabajo que, a veces, como en el caso concreto del Salustio, duraba muchos meses.

Una prolongación tan larga del proceso de edición tuvo que reflejar alguna huella en la impresión de los ejemplares distanciados por el diferente comportamiento de las tintas, pero la percepción de este detalle en Ibarra, quizás por su habilidad artesanal, únicamente está al alcance de los profesionales. Sí es posible observar, sin embargo, que en algunos ejemplares se ha escapado al grabador un suave reborde en ciertos márgenes que no se aprecia en otros. Esta particularidad se debe, sin duda, a una negligencia o descuido del artífice, pero es dificil precisar si la presencia de dicha marca se produce por la incorrecta colocación de la plancha o por corrimiento del papel en el bastidor. 
El infante Don Gabriel y el Inspector Ibarra...

Las diferencias que se aprecian en el formato son bastante sorprendentes, pues van de $34 \times 23^{\prime} 5$ a $36 \times 25^{\prime} 5$, lo cual significa dos centímetros de diferencia en largura y anchura, muy apreciable para los bibliófilos. El formato del papel en la tirada especial, que es intonso, comprende 36 ' $5 \times 27$ '5 centímetros, el cual parece ser el punto de partida general antes de los cortes exigidos por la encuadernación. Precisamente, este último proceso de vestir o engalanar el libro es el que manifiesta mayores peculiaridades en los ejemplares individuales, incluso de cada grupo. En la encuadernación de lujo, el marroquí de la cubierta se presenta bruñido en granate en unos ejemplares y en azul en otros. Las guardas son de moaré azul en unos y rosas en otros. En la colección Usoz, la Biblioteca Nacional conserva un ejemplar, con el sello de dicho donante, representativo del presumible tercer grupo de gran lujo con una admirable encuadernación en azul marengo con elementos renacentistas y concepción muy geométrica, orlada en las tapas con tres filetes de distinto grosor con eclosiones florales y de rocalla. Cubierto con una tela protectora, el descosido de uno de los ángulos permite ver el lomo cuajado con seis parejas de nervios, separados por surcos con gruesos filetes como rios de oro en estrechas gargantas. El tejuelo lleva en oro, sin otro aditamento, el título de "Salustio en español", el mismo que llevan los demás ejemplares, algunos de ellos incorporado en distinto color de piel. Las guardas de tela roja se decoran con doradas orlas, llenas de originalidad y brillantez.

\section{La tirada especial}

Los 120 ejemplares de la tirada especial no tienen excesivas novedades en el aspecto tipográfico. El papel es el mismo, pero más generoso en el sentido de que lleva cuatro hojas de respeto, en lugar de dos, y los márgenes son más amplios por estar intonso, pero bien encajados sin barbillas ni irregularidades notables. El ejemplar conservado en la Biblioteca Nacional incorpora en la cuarta hoja de respeto un estudio manuscrito para demostrar que una traducción 
publicada algún tiempo antes, no era apenas más que una copia de una de Vasco de Guzmán, conservada en el Escorial.

La encuadernación de este ejemplar, sin embargo, se reviste de lujo y esplendor con un gofrado que cubre con generosidad y penetración los bordes y los ángulos. La rueda de la orla, la del contracanto y los hierros en general se abigarran y ensanchan. La rocalla de los ángulos se desborda respetando en el centro un espacio vacio, casi circular. Fascinante resulta el moaré de las tapas de terciopelo de color amarillo anaranjado, con cuya increible suavidad un ciego podría al tacto concebir la aurora ${ }^{13}$.

\section{Los historiales}

Una vez salidos de las prensas, los ejemplares de una edición se difunden, como mensajeros de cultura, en las más diversas, y a veces insospechadas, direcciones. Su función es servir, infundir conocimientos y disfrute en una situación de permanente disponibilidad como consejeros fieles, como silentes juglares. En particular, aquellas buenas ediciones, las ediciones que suscitan veneración y respeto, llevan inherente una garantia de longevidad y permanencia frente a la contingencia de los señores a los que sirven. Éstos fenecen, aquéllos permanecen y van enriqueciendo su historial de solera nobiliaria. Los franceses a ese historial llaman provenance que indica los hitos de servicio desinteresado y fiel de un libro, señalado por notas manuscritas de propiedad, firmas, ex-libris, sellos, armas, logotipos, etc., de antiguos poseedores orillados por el tiempo. La procedencia derivada de personalidades ilustres por su cuna, por su sabiduría, por sus hechos y hazañas, por su popularidad, etc., añaden prosapia y nobleza a los libros. Uno de los ejemplares depositados en la Biblioteca Nacional lleva el sello de pertenencia de Pascual Gayangos, otro se deposita en la colección Usoz y el historial de un tercero de los examinados, de propiedad particular, se inicia por la pertenencia al cortesano conde de Gualqui, quien en 1.819 lo ofrece en obsequio con dedicatoria manuscrita al príncipe de Laval Mommorency, par de Francia, mariscal de campo, embajador a la sazón de Francia en la corte del rey católico 
e inmediata figura influyente de la diplomacia europea, de cuyo servicio pasó al de François Guizot, ministro de Luis Felipe I y uno de los más preclaros historiadores clásicos de la Revolución Francesa, acreditado por el sello de pertenencia a su biblioteca. La mayor parte de las obras raras y preciosas terminan por descansar a la postre en un destino, en la práctica definitivo, de una colección o biblioteca institucional, pero este último ejemplar pasó a poder de un librero francés, de cuyas manos regresó al lugar de donde había salido hace más de doscientos años, precisamente en el hotel donde se celebró la citada Feria Internacional del Libro, situado a menos de cien metros de donde vio la luz.

\section{Notas}

1 UPDIKE: Daniel Berkeley, Printing Types, their History, Forms and Use. Cambridge, Massachussets, 1922. 2, 55 y 72-3.

2 Ambas referencias en RUIZ LASALA, Ignacio, «Joaquín Ibarra y Marín (1725-1785)", en Joaquín Ibarra y Marín, impresor, 1725-1785. Ibercaja: Diputación General de Aragón, Zaragoza, 1993, 82.

3 Encyclopédie Methodique: Arts et Métiers Mecaniques III. Paris, 1794,481 . El anterior a este tomo interrumpió la publicación en español de las diversas series de materias de la Enciclopedia que desde 1787 venía haciéndolo Antonio de Sancha, debido a las turbulencias y tensiones de las relaciones hispanofrancesas y del estallido de la guerra entre ambas naciones en ese año de 1794 .

4 Paredes Alonso, Javier, Mercaderes de libros. Cuatro siglos de historia de la Hermandad de San Jerónimo. Fundación Germán Sánchez Ruipérez: Pirámide, Salamanca, Madrid, 1989, 28.

5 Moll, Jaime, "El entorno de dos letrerías del siglo XVIII", en Joaquin Ibarra...157-8; De la Imprenta al Lector. Estudios sobre el libro Español de los Siglos XVI al XVIII. Arco/Libros, Madrid, 1994.

6 Martínez Ruiz, Julián, Las Ciencias Naturales y la Real Sociedad Bascongada de Amigos del País en el siglo XVIII. San Sebastián, RSBAP, 1962, 63-5. Según costumbre en las ofertas, el conocido cristalógrafo Romé de l'Isle redactó un catálogo de la colección, publicado en Paris en 3 vols. en octavo en 1767 con el título: Catálogo sistemático de las curiosidades de la naturaleza y del arte de que se compone el gabinete de Mr. Dávila.

7 LOPEZ VIDRIero, María Luisa, "La imprenta en el siglo XVIII", en EsColar Sobrino, Hipólito, dir., Historia llustrada del libro Español. De los Incunables al siglo XVIII. Fundación Germán Sánchez Ruipérez: Pirámide, Madrid, Salamanca, 1994, 237. 
8 Schaefer, Ernesto, El Consejo Real y Supremo de las Indias 1. Sevilla, Universidad de Sevilla, 1935, passim (Indice).

9 Véase OlaEchea LABAYEN, Juan B., "Nueva visión de la rareza de los libros", en Homenaje a Justo Garcia Morales. ANABAD, Madrid, 1985, 471-489.

10 Sarrailh, Jean, La España Ilustrada de la Segunda Mitad del Siglo XVIII. Fondo de Cultura Económica, Madrid, 1957, 368.

11 Michaud, J. Fr.: Biographie Universelle ancienne et moderne 20. Paris 1854, voz Ibarra.

12 La obra citada en la nota 2 presenta la «biobibliografía" de los artistas que participaron como colaboradores en la edición. Más detalles: CARRETe PARRondo, Juan "El grabado en el siglo XVIII. Triunfo de la Estampa Ilustrada”, en Summa Artis. Historia General del Arte 31: El Grabado en España. Espasa Calpe, Madrid, 1987, 395-644.

13 Los referidos inventarios han sido publicados posteriormente por Moll en su obra De la imprenta al lector: estudios sobre el libro español de los siglos XVI al XVIII. Arco libros, Madrid, 1994, en la que afirma que era habitual que talleres especializados se encargasen de la estampación de estampas finas.

14 Cuatro de dichos ejemplares, más otro in tonso, están en posesión de una familia madrileña, reservados para sus cuatro hijos. ¡Bella herencia! De los ejemplares cotejados, el de mayor historial pertenece a otra colección particular y los demás a propietarios particulares o a libreros, además de los tres mencionados de la Biblioteca Nacional. 